\title{
Review of Freud's Psychoanalysis Approach to Literary Studies
}

\author{
Azadkhan Niaz \\ Lecturer \\ English language and literature Department \\ Kabul University, Kandahar, Afghanistan \\ E-mail: azadkhan.niaz@google.com \\ Sultn Mohammad Stanikzai \\ Lecturer \\ English language and literature Department \\ Kandahar University, Kandahar, Afghanistan \\ E-mail: stanikzai.sultan@gmail.com \\ Javed Sahibzada \\ Education Faculty's Research Center head \\ English Department, Kandahar, Afghanistan \\ E-mail: sahibzada.javed@gmail.com
}

\begin{abstract}
The purpose of this review article is to identify theories of Psychoanalysis by Sigmund Freud that play major roles in interpreting literary works. Psychoanalysis is among one of the modern theories used in literary analysis. Whether psychoanalysis has close connection with literature or not has been most controversial issues for many readers and least appreciated. In spite of being one of famous approach for interpreting literary text, it has become one of the mechanisms for interpreting hidden meaning of the text. The finding of this paper revealed Psychoanalysis is not simply branch of medicine, it has helped and is used to understand various fields as philosophy, culture, religion and first and for most used in literature. It also revealed that there is similarities and controversial issues between Carl Jung and Sigmund Freud's theories of psychoanalytical criticism. Id, which is part of human personality playing a major role in forming literary work for its repressed behaviors, laid in unconscious mind. The human actions which are suppressed feelings because of superego and can be expressed with the help of Ego which balance the conflict between id and superego in the right time in form of dreams, art, literary work and slip of tongue. Psychoanalysis approach is used to analyze piece of art by investigating closely the author and his/her life and literary work for providing evidence in analyzing, one or more of the character's behavior and inspiration, the audience' appealing and motivation to which react more closely or less unconsciously and the text for examining the role of language and symbolism in the work.
\end{abstract}

Keywords: Repression, Personality, Dream, Unconscious, Symbol

\section{Introduction}

Literature is considered to be fiction, yet nothing is completely fiction even fiction has source of truth that aim to be interpreted in different ways either stated directly or indirectly through the actions of characters, symbols (associative meanings of the words). What makes literature different from ordinary work is beauty, experiences and moral. A literary work must have all or at least one of them to be considered literature. That is beauty of the text rely on the associative words or simply how a writer artistically crafted text to interpreted particular theme. It can be through use of familiar issues to the readers or through using remote topics. Whatever form of literature, it should be oral or written with hidden meanings or obvious meaning a work of art have particular audience or generally written or crafted with other ways through plays or movies its needed to be understood by their audiences. In order to interpret work of art various literary criticism schools: historical criticism, have suggested different methods. Taking into accounts the twentieth century's literary criticism as Formalisms leaded by Victor Shklovsky, Boris Eichenbaum, Mikhail Bakhtin, Roman Jakobson, John Crowe Ransom, William K. Wimsatt, Monroe C. Beardsley, T. S. Eliot. Psychoanalytic Criticism famous for Freud and Lacan contribution. Structuralism Ferdinand de Saussure, Roland Barthes. Deconstruction Jacques Derrida. Feminist Criticism Virginia Woolf, Simone de Beauvoir, Elaine Showalter, Michèle Barrett, Julia Kristeva, Hélène Cixous. Reader-Response and Reception Theory 708 Edmund Husserl, Martin Heidegger, Hans Robert Jauss, Wolfgang Iser, Stanley Fish. Postcolonial CriticismFrantz Fanon, Edward Said, Gayatri Chakravorty Spivak, Homi 
Bhabha, Henry Louis Gates, Jr.. New Historicism Stephen Greenblatt, Michel Foucault (Habib, 2008 p.7). All of them have exposed various theories and principles for interpreting a piece of art. This paper attempts to explore psychoanalytical criticism for interpreting meaning.

Psychoanalysis is an American concept, with a politically intense and important gathering of people encouraging for reasonable and specialized change. Therapists have declared new revelations in various discipline. A famous figure in field of psychoanalysis studies_-Sigmund Freud-who began to spread his thoughts regarding the presence of unconscious mental procedure, he didn't meet by any methods generally with disavowal and incomprehension, as he himself needed his pursuers to have.

Freud have coined the term "psychoanalysis in 1896 and worked and explored it in the next forty years of his life to develop principles, method and techniques for it. In these forty years, he was able to details many theories of his thought on mental life. As the interpretation of dreams, structural model theory of mind, and the technique of psychoanalysis (Beystehner, 1998). Eventually psychoanalysis became famous and by 1925, it was established around the world as successful movement. Though Freud was considered radical by many in his profession, but he was soon accepted and well-known worldwide as leading expert in the field of psychoanalysis.

Psychoanalysis is not simply remained branch of medicine, it has been used and helped to understand various fields such as philosophy, culture, religion and first and for most used in literature. Psychoanalysis as the modern theory is used in literature and has two basic meanings: firstly, it's used as methods of treating mentally disordered people. Secondly, it is used to explain human mind and its various complexities (Hossain, 2017).

Dreams like books are fictions the creation of the mind. Even though, with light of the variety by their definitions, they may not be really true. As novels, fantasies they also have some truth to distinguish. However, like a novel it may be interpreted before true statement to be covered on. Psychoanalysis is considered as theory of the human personality that describes the personal identifications by which the genders are separated and controlled. psychoanalysis addresses itself issues of dialect taking internal motivation taking into consideration the Freud's concern who focused language articulation based on individual intrinsic motivation. He considered the impact of desire in language and it's all types of typical relationship.

Such argument leads literary critic to compare abstract writings with dreams which express the mystery of unconscious desires and tensions of the writer and that an artistic work is a production of the writer's own particular mental events. The analysis draws out the unconscious part of articulation through its focus on the relationship in the middle of origin and social division. A critic may analyze by the use of psychoanalysis criticism a specific character in an abstract work, however, it is to be understood that every single of such character are projections of the creator's head. Expert have emphasized specific elements of the hypothesis and factors that separate from other mental sciences, raising question on whether psychoanalysis is a science with any means, and also whither analysist think innovation for their applicable technique (Beystehner,1998).

Psychoanalysis can be specifically divided into three types: a) individual psychic dynamic (a hypothesis of mental and development), b) social behavior (a method used in clinical treatment) and C collective social life (a universal method of observation regarding human phenomena) (Stangor, \& Walinga, n.d.).

As mental analysis theory and strategy is an investigation of unconscious mental procedure, which is basically considered psychoanalytic theory or it is a type of clinical treatment that is described by its particular clinical methodology and used specialized approach. For instance, the power of motivation in particular action and analysis of that for interpreting unconscious inspirations and behavior. The analysis draws out the unconscious part of writing through its language on the relationship in the middle of sexual and societal spirit. The most continuing of this theory the Oedipus complex, a theory of the development of sexual personality. In other words, the Oedipus complex is the desire where male baby up to the age five-year longing the desire to rub out the father and opposite into the sexual partner of the female parent.

When a kid acknowledges he can't hold his momma as a sexual partner, he then tries for the social rights which will grant him his own sexual partner outside and from opposite sex. This theory has been intensely criticized for its reliance on heterosexuality and the patronage of a customary (Freud, 1949). The Oedipus complex is for Freud the core of longing, restraint and sexual personality. Its buildup is a deep rooted uncertainty towards the keeping and infringing upon of taboos and laws.

Psychoanalysis is among one of the modern theories used in literary analysis for whether it close connection with literature has been most controversial and for many. It is least appreciated in spite of being one of famous approach for interpreting literary text. According to Hossain (2017) psychoanalysis is regarded one of the interesting and satisfying approach in the application of interpretive analysis. Psychoanalysis became one of the mechanism for interpreting hidden meaning of the text. It helps one in understanding complex symbols, actions, metaphors, and settings in a literary work. However, many psychoanalysts believe that this approach applies to any literary work. Yet, most critics opposed this notion that one approach cannot adequately explain everything about a complex work (Davis, n.d.).

Psychoanalytical theories assume the existence of unconscious states of internal that motivate external behavior (Sollod, Monte, \& Wilson, 2008). Freud was not the first who work in psychoanalytical criticism, yet when we are talking about psycho analytical criticism, he appears as an important figure in our discussion. The two main reasons which make Sigmund Freud prominent in psychoanalytical criticism studies are: firstly, Freud's theories are either indirectly or directly 
concerned with the nature of the unconscious mind. Before Freud "sane" was supposedly considered as conscious and rational only. But Freud went further, suggesting that the powers encouraging women and men are chiefly and mainly unconscious. Secondly, the approach of psychoanalytic criticism to literature not only rests on the theories of Freud; it may even be said to have begun with Freud who was Interested in writers; especially, those who depend greatly on symbols. Thus, it would not be possible to understand psychoanalytical criticism without taking into account the Freud's contributions. Through this paper we have tried out best to briefly touch some of his important works which are crucial in field of literary work and are vital for interpreting literary work with help of psychoanalysis.

\section{Objectives}

- To identify similarities and differences between Carl Jung and Sigmund Freud in theories of Psychoanalysis.

- To identify theories of Psychoanalysis by Sigmund Freud which play major roles in interpreting literary works for hidden meanings.

- To clarify how psychoanalysis theories of Sigmund Freud are used to analyze literary work.

\section{Research Questions}

- How are Carl Jung and Sigmund Freud similar and different in their theories of Psychoanalysis?

- Which theories of psychoanalysis by Sigmund Freud have major roles in interpreting literary works for hidden meanings?

- How do psychoanalysis critics look at Freud's theories in analyzing the literary work?

\section{Methodology}

This literary review article is descriptive in nature where those theories of psychoanalysis by Sigmund Freud are interpreted which are plying significant role in analyzing literary works. The principles and elements from Freud works has been taken as a model for literary criticism of hidden meanings and the way these principles and theories are used to interpret piece of literary works and identifying motive behind producing this piece of art.

\section{How are Carl Jung and Sigmund Freud similar and different in their theories of Psychoanalysis?}

Jungian criticism has explored the connection between literature and what Carl Jung called the "collective unconscious" of the human race: "... racial memory" where whole human show itself. Carl Jung was one follower of Freud since they had shared same interest in unconscious. He was an active member of the Vienna Psychoanalytic Society (formerly known as the Wednesday Psychological Society). With Freud's request, he was elected as a president of International Psychoanalytical Association in 19I0. In the lecture tour in America Jung has publicly criticized Freud theory of "Oedipus Complex" in 9I2 for Freud emphasis on infantile sexuality and it lead them to split in the following years and Jung opened his own version of psychoanalytic theory (McLeod \& Bowlby, 2008). The disagreement between Jung and Freud can also be found in the "Theory of the Libido" Jung disagreed in with Freud according to Jung libido is not just sexual energy, yet it is generalized psychic energy (McLeod, 2018)

Despite they both agreed on psyche part of personalities "id, ego and superego" and as well in the importance of "unconscious" in relation to personality, but their notion in "psyche part" is different. For instance, Jung believed the two form of unconscious the first as Freud version personal unconscious which contains temporary forgotten and repressed memories. He called them complex memories that include collections of attitudes, thoughts, feelings which emphasize on single concept. however, he believed the personal complexes are surface level which their effects are included from present and future, but on the other hand, Freud believed these are only the personal memories of childhood and there are no future effects involved.

The other disagreement is in the purpose and nature psychic energy. According to Jung, the purpose of psychic individual's psychic energy can be inspired from several factors, thus individual's behavior is lead in that way. Individual maybe motivated creatively, spiritually and intellectually and these individual's motivation source consequently lead one to seek pleasure and avoid conflict. On the other hand, for Freud individual motivation are inspired from personal source from past memories mostly from memories of childhood mainly relayed on sexual inspiration ( Stangor, \& Walinga, (n.d.).

However, the most controversial part between Jung and Freud is the collective unconscious in personality theory. According to Jung, level of unconscious is the shared with other members of individual's surrounding which contains latent memories from our ancestral and evolutionary past. He thinks individual born in the world where there are innate memories with hidden meaning from his/ her ancestors (Shelburne, 1988, p.27). According to Jung human mind has innate characteristics which imprinted such as fear of darkness insects etc. and universal and shared tendencies of ancestral. Jung called these ancestral memories and images archetypes (Shelburne, 1988, p.67).

According to Jung Archetypes are thought and images that have universal meanings across cultures and they are show up in dreams art, religion and literature. He also believes symbols are very similar in different cultures, for they have appeared from archetypes shared by all human being and they are part of collective unconscious. There is another archetype for Jung "anima/animus" which he called it mirror image of human being which individual find it in her/ his opposite sex. For example, 
male find his unconscious tendencies in female and vice versa. Each sex displays attitudes and behavior of other by quality of his/ her (anima, animus) as they have lived together for centuries. "Oftentimes, males describe anima as appearing as if someone drew the picture of their perfect woman". To put it in sample words each male has anima (feminine side of male) a dream girl which make that man complete and for a girl it would be animus (masculine side of female) a dream boy where she searches for perfect life partner. Searching for perfect anima/ animus can create distraction in male and female relationships. As male projecting his anima onto a woman in his life and expects her to live up to that image he has it as his anima. It's said that this tendency begins in early childhood and can continue throughout his life. And the same goes for female and such projection will case denial for the other who is currently with her in the relationship (Radowl, 2018). Likewise, there is another different between Jung and Freud and that is Freud called the id animal side of human personality but on the other hand Jung believed the id the source of creative energy and as well distractive of human personality. Jung claimed that many of human problems are due to their unawareness of it. Thus they can solve these problems if they alien their instinctual foundation a part of anima and animus which ply an important role in motivation.

Carl Jung and Sigmund Freud both have worked in Psychoanalytical criticism. The have shared similarities and differences in their theories and believes. The differences are for example, according to Freud libido is source for psychic energy which is mainly function for sexual fulfillment on the other hand, Jung generalize source of psychic energy which he thinks it is playing roles in motivating various parts of behaviors. Likewise, Jung believed unconscious is place where individual's repressed memories are kept and these memories are belonging to individual's past and future and they are belonging to individual's ancestral and personal memories. On the other hand, according to Freud these are repressed and unacceptable desires which are specific to that individual only. According to the Freud individual's behavior are caused by past experience mainly from childhood, but Jung claims these behaviors are inspired by past and future experiences of individual.

\section{6. "Which theories of psychoanalysis by Sigmund Freud have major roles in interpreting literary works for hidden meanings?"}

\section{I Psychoanalysis Criticism}

Sigmund Freud, in his "Structural Model theory of personality", states that each individual's personality is made of three parts: The Ego, the Superego and the Id. These three together works to make complex human personality. Thus Psychoanalysis is the procedure of applying what humans know about these three parts of one's personality and to discover the ways how a person behaves. Literary critics often analyze the actions of literary characters in the work of literature by applying the three personality structures id, ego and superego which Freud identified. As critics explore the ego, superego, and id of characters in a literary work, they stress on the ways how these parts based the behaviors of the characters and consequently affect the work as a whole. This process is called psychoanalytic criticism (Wali (20II).

\subsection{Structural Model of Personality}

According to Freud the id is the part of the personality that holds our basic desires. such as thirst, anger, hunger and the desire for instant fulfillment or release. Freud, believes human being are innate with their id. The id is a vital part of our personality since as infants; it allows us to get our primitive needs met. Freud believed that the id is based on our desire principle. The id wants whatever feels worthy at a time, with no concern for the other state of affairs of the situation. As id have the power to influence ego and can easily bring self -pleasure, it is sometimes described by a "devil sitting on somebody's shoulder" A Research Guide. (2010). As this devil sits there, he tells the ego to base performance on how the action will affect the self, specifically how it will bring the self-pleasure.

"Superego" The superego is the part of the personality that embodies the conscience and the moral part of us. The superego grows due to the moral and ethical restraints located on us by our caregivers. It commands our belief of right and wrong. The superego is associated with an "angel sitting on one's shoulder" A Research Guide. (2010). Superego telling person to control the ego's behaviors and to base behavior on in a way the action is influenced by moral part of human personality.

"Ego" The ego is the part of the personality that keeps a sense of balance between desires we have in (our id) and our conscience (our superego). The ego is based on the real belief. The ego knows that other people have needs and desires and that sometimes being impulsive or egoistic can hurt us in the end. In addition, it is the ego's job to come across the needs of the id, but taking into consideration the reality of the situation. The ego, in other words, has duty to balance id and superego. The ego is represented by an individual, with a devil (the id) on one shoulder and an angel (the superego) on the other (Freud, I949).

The "Unconscious" and Its Origins: to understand the importance notions related to conscious and unconscious that have been set by Freud in his theory of the human mind, it is vital to understand the division of it. Freud has divided the human mind into three regions: a "conscious" region he refers to a place where individual's current thoughts, feelings, and effort live. a "preconscious" which is also known as "subconscious" according to Freud it is living place for things individual can recall or retrieve from her/ his memory. And "unconscious" is the deepest level exist which most of the time we are unaware of it. It is in origin of the procedures that motivate our behavior, including original and instinctual desires (Encyclopædia Britannica, 2017, December) 
The unconscious in personality theory of psychoanalytic by Freud is stack of feelings of the unconscious mind, desires, thoughts and memories that are outside of our conscious awareness. Most of the matters of the unconscious are unacceptable or unpleasant, such as feelings of anxiety, pain, or clash. According to Freud, the unconsciousness continues to impact our behavior and capability; however, we are not aware of the following deep influences:

"Repression" is act to keep information and memories far from conscious awareness. Individual keeping away memories from his/ her conscious awareness and these memories don't disappear just; but they remain to affect our actions. Occasionally we fix this consciously by driving the unwelcome information out of our consciousness which is called suppression. In many cases, however, this exclusion of nervousness provoking memories from our consciousness is believed to occur unconsciously (Tyson, 2014, P.I5 2014). Adam says, "Freud found two mental marvels, "repression" and "the return of the repression." (Adams, 200I, p. 60).

"Oedipal complex" Sigmund Freud used the term in his theory of psychosexual stages of growth and describe desire feelings of a boy for his mother, anger and jealously towards his father. Basically, the feelings which a boy has toward his father is that he feels like he is rival with his father for possessiveness of his own mother. He thinks his own father as rival for her mother affections and attentions (Freud, 1899). According to Freud, the boy wishes to possess his mother and replace himself to his father, who he views as a rival for his mother's fondness. The Oedipal complex happens in the "phallic stage" of psychosexual development between the ages of three and five. The phallic stage helps as significant point in the development of sexual identity. The similar stage for girls is known as the "Electra complex" in which girls feel desire for their fathers and being jealous of their mothers.

"Defenses" is the processes through which the issues of our unconsciousness are retained in the unconscious. Defenses include selective perceptions that is seeing and hearing only those we feel that we can handle. Or selective memory is memory which is modifying our memories so that we don't feel overwhelmed by them or painful. We are trying to forget those painful incidents entirely or rejection of believing that the difficulty doesn't exist or the hostile incident never happened. Avoidance of being away from people or circumstances that are accountable to make us worried by moving up into unconscious. For instance, repressed the experience or feeling "displacement", taking it out on someone or something less threatening than the person who has really affected our fear, hurt, frustration, or anger projection, ascribing our fear, problem, or guilty desire on someone else and then accusing him or her for it. In order to reject what we have in ourselves in regression, the temporary coming back to a previous psychological state, which is not imagined but relived just. Regression can include a reoccurrence either to a pleasant or a painful experience. It is a defense, since it takes our judgments away from some current trouble (Wali, 20II).

Human being according to Freud go through various stage of "Defense Mechanism": Repression he adds because of ego individual's disturbing thoughts are kept away and became parts of unconscious. These thoughts maybe for example aggression or jealousy of parents such as Oedipus complex which child may not fulfill it simply lead to unconscious. These thoughts may come in form of jokes, comedy and comic (Holland,1999). The person may go to the stage of "Denial" refusing to face the fact. Individual do not want to experience the reality. Lover refuse to admit that marrying that person is impossible with current condition. "Projection" stage where individual attributing his/her blame or anger on the other person since superego trained person that to hate the other is not a good habit so the person could blame the other for he/she is hating him or her. These source of behavior can cause displacement in individual's life for example, the cause of aggression may be satisfied by substituting the other person who is not real cause of anger, but individual taking out anger on him/her. Such as satisfying anger on boss lead a person to fight at home. A person in stress from earlier stage or experience of unconscious may go to the stage of regression which consequently lead that person to the temporary or long-term return of the ego to an earlier stage of development of that particular experience, instead of handling unwanted desires in a more adaptive way. These unwanted desires can lead affected person to a more positive socially and ethically acceptable manners and this stage is known as "sublimation". It causes person to satisfy his/her desire in substitution of the other object. For example, aggressive emotions which a person may put in more positive and constructive way (McLeod, 2017). Critics have looked out in literary work for identifying associative themes of these defense mechanism and reader's response to them. Holland (1999) in his article The Story of a Psychoanalytic Critic is referring to his earlier work of investigating reader response theory. He claimed individual associating various symbols in literary work beside wishes and jealousy related to Oedipus experiences there were other symbols associated with literary text. He thinks the Shakespeare's play may have imagery and fantasy which may began with pre-oedipal with these characters but with different level of fantasy.

According Holland (1999) defense are the conflict different psychic agencies and reality which repress different sensory evidence. We repress many incidents, we project different thoughts to substitution with opposite in result different defense are causing different literary form, structure and techniques: "splitting, parallelism, repetition, contrast, omission and all the phonetic language which serve in psychoanalytic terms as a displacement". He believes as there are different levels of defense from pre-oedipal stage there is different stage and level of mind processors are involved. These literary text also result in different level of fantasies with various form, text and structure which transform the work of art into unified theme which individual take meaning of text whatever individual reader is searching for. 


\subsection{Dreams and their Symbols}

Freud believes dreams have two content concealed and obvious. He believes concealed and obvious content of a dream is the secret psychological meaning of a dream. According to Freud, the content of dream is related to wish fulfillment and he suggested that dreams have two types of content: manifest content and latent content. The manifest content is the real literal subject-matter of the dream; on the other hand, the latent content is the underlying meaning of these symbols. Moreover, Freud believes that the latent content of dreams is repressed and concealed by the subconscious mind in order to protect someone from thoughts and emotions that are hard to deal with. Dreams became a way of expressing those repressed feelings which are unacceptable in real life situation, because of our social, ethical or any other (superego) restrictions (Freud, I899).

Freud claims that in order to understand the dreams and to recognize their symbols, Primary revision of the dream is vital which in turn covers "displacement" and "condensation". Displacement which is an element of dream work that covers the emotional meaning of the latent content by confusing the vital and insignificant portions of the dreams (Freud, \& Strachey, I916).

On the other hand, condensation which described as Many different thoughts and concepts which are represented inside the length of a dream. Beside displacement and Condensation there is another procedure called "symbolization". Freud illustrates that symbolizations are procedure censors the suppressed thoughts contained in the dream by counting objects that are meant to symbolize the latent content of the dream the second interpretation is the secondary revision. During the last stage of the dreaming process, Freud recommended that the bizarre elements of the dream are reorganized to make the dream comprehensible, thus producing the manifest content of the dream could have recognized by understanding the role psychic parts.

According to Holland (1999) "what we wish we also fear and what we fear we also wish" which this wish and fear can be understood when we have unity with literary text. We have conflict with desire and ethics. The latent symbols of literary text can be understanding when one knows what he she fears and wishes.

\section{How do psychoanalysis critics look at Freud's theories in analyzing the literary work?}

Psychoanalytical critics are looking at the psychic part and the meaning of sexuality. The psychic part of personality is divided further into three parts. These three features of personality are the id, the ego and the superego. They work together to generate complex human behaviors. The id is the only element of personality that is innate in human being. This feature of personality is completely unconscious and involved of the natural and primitive behaviors. Based on Freud's analysis, the id is the foundation of all mental energy, making it the prime part of personality. The id is result of the desire principle, which struggles for immediate fulfillment of all pleasure desires, needs, and wants. If these needs are not fulfilled immediately, it leads to a state of anxiety or tension. However, straightaway fulfillments of these needs are not always accurate or even possible. According to Freud, the id attempts to resolve the strain shaped by the pleasure principle by the primary process, which includes making a mental picture of the wanted object as a way of satisfying the need. The ego is the part of personality that is responsible for dealing with reality.

In accordance with Freud's view, the ego grows from the id and confirms that the impulses of the id can be conveyed in a way suitable in the actual world. The ego functions based on the real principle, which strives to please the id's desires in accurate and socially appropriate ways. The reality principle balances the costs and benefits of an act before deciding to act upon or abandon desires. In many situations, the id's desires can be fulfilled through a process of late fulfillment. The ego will ultimately let the behavior, but only in the suitable time and place. The final part of personality to grow is the superego. The superego is the part of personality that holds all of our internal moral principles and models that we get from both parentages and society for our logic of right and wrong. The superego offers procedures for building decisions. According to Freud, the superego arises to develop at around age five. The superego functions to expertise and educate our behavior. It acts to suppress all improper desires of the id and struggles to make the ego work upon principled standards rather that upon realistic principles.

Focus of Psychoanalytical Criticism and Literature: It looks natural to reflect about literature in expressions of dreams. Like dreams, literary works are fictions, creations of the mind that, though centered on reality, are by description not exactly true. Similar a literary text, a dream can have specific reality to express, yet, similar to a literary work, it might need to be analyzed before that reality can be grasped. We can live through idealistic fictions, much as we can by daydreams. Scary novels and nightmares shake us in greatly the similar way, sinking us into an atmosphere that continues to cling, even once the last section has been read or the alarm clock has called. The idea that dreams let such mental surveys, obviously, similar the comparison among literary works and dreams, has a great deal to the thinking of Sigmund Freud, the famous Austrian psychoanalyst who in 1900 published a seminal essay "The Interpretation of Dreams".

Psychoanalytic criticism has inspired our seniors or even teachers studied with, the works of scholarship and criticism which they read, and the critical and creative writers we read as well. What Freud done was to develop a language that described, a model that clarified a theory that covered human psychology. Most of the elements of psychology he tried to find to describe and explain are existent in the literary works of different time and cultures, from Sophocles' Oedipus Rex to Shakespeare's Hamlet to the literary works being written in our own time (Sparknotes. n.d.). When the great novel of the twenty-first century is written, most of these same elements of psychology will perhaps notify its dialogue as well. If by understanding human 
psychology according to Freud, we can appreciate literature on a new level, then we should familiarize ourselves with his perceptions.

Freud's theories are either indirectly or directly concerned with the nature of the unconscious mind. Freud was not inventor for the notion of the unconscious; before him others had recommended that even the supposedly "sane" human mind was conscious and rational only at times, and even later at possibly only one level. But Freud gone further, suggesting that the powers encouraging women and men are chiefly and mainly unconscious (Jeneng, T.n.d.).

Then, Freud strongly advanced an old idea that the human mind is essentially dual in nature. He called the predominantly passion, illogical, unidentified, and unconscious part of the psyche the id, or it. The ego, or "I," was his term for the predominantly rational, logical, orderly, conscious part. Other aspect of the psyche, which he named the superego, is really a projection of the ego. The superego almost seems to be outside of the self, making moral judgments, telling us to make sacrifices for good causes even though self-sacrifice may not be quite logical or rational. And, in a sense, the superego is outside, because much of what it states is to do or think we have learned from our parents, our schools, or our spiritual foundations. What the ego and superego tell us not to do or think is not to be repressed and forced into the unconscious mind.

One of the most important contributions by Freud in the study in the mind is the theory of repression. The repressed memories sustain in the unconscious mind and they have been placed there by consciousness, which acts as a censor, motivating underground unconscious or conscious feelings or instincts that it supposed to be unacceptable. Censored memories are often comprised childhood sexual wishes. Freud claimed these repressed memories which lied in unconscious mind, arise only in hidden forms in dreams, in language slip of the tongue that are so called (Freudian slips), in creative work that may create art and including literature (Bilcik, 2018). According to Freud, all of us have repressed wishes and fears. we all have dreams in which there are repressed feelings and memories appear masked, and so we are all possible candidates for dream interpretation (Swift, 1995).

One of the unconscious desires most commonly repressed is the infantile desire to be replacing the parent of our own sex and take his or her place in the affections of the parent of the opposite sex. Freud called it "Oedipus complex." Freud referred to the whole complex of feelings by the word "Oedi-pal," naming the complex after the Greek tragic hero Oedipus, who unwittingly killed his father and married his mother (Encyclopædia Britannica, 2018). The desire actually includes a number of various but related wishes and fears. A boy and it should be observed in passing that Freud concerns himself mainly with the male may have fear that his father will castrate him, and he may have wish that his mother would return to nursing him.

According to Freud the reason behind oedipal desires and repressed fears by the conscious side of the mind and effects to them after they have been censored, these wishes are less or more characteristic of typical human development. In dreams, mainly, Freud found plenty marks that such desires persisted. Therefore, he conceived that natural wishes, when recognized as "wrong," may be repressed but not destroyed. In the unconsciousness, these desires take on garb of symbolic, regarded as nonsense by the awakening mind that does not identify their meaning. For Freud the importance of dreams was no different than his belief that there is an unconscious side to the mind.

Again, it was the amount to which he advanced a theory of how dreams function and the scope to which that theory helped him, by comparison, to recognize far more than just dreams, that made him rare, important, and prominent beyond the borders of medical schools and psychiatrists' areas. In order to interpret the text readers, associate the text with various experience or perception they have. Holland N. N. which stated in Holland (I999) with his colleagues have investigated reader response to the text, they have come out with concept that individual have various sensory of perception, which differ from individual to individual and these also different from culture to culture. Readers interpret the text by acknowledging their own role and their perception in it. They further reveled one can only perceive the text through human perception shaped by human identity. Thus the areas human being process noun are different from the areas they process verbs, also there is different between writing structures of different language. For example, English brain may process English articles differently from German speaking brain process German Articles.

Meaning are not interpreted simply but for interpreting any noun assemble variety of information from different places in the brain depending on the experiences sensory perception and the context and history of a words. For psychoanalysis it is important to look for the word where its located, what information it has and what emotion accompany it. For Freud these experiences are highly personal. Human mind contents different memories yet for psychoanalyst long term memories are important where there is two kinds explicit memory containing general facts as well memories of personal events and second types contain implicit or non-declarative memories which are unconscious. The events which individual have experience from childhood many can be still remembered such how learned to ride a bicycle walk etc. but we don't remember memory of early childhood or the age of 6 months (Holland, I999).

. Freud's interest in literary artists encouraged him to create some unfortunate generalities about creativity; for example, in the twenty-third lecture in Introductory Lectures on Psycho-Analysis (1922), he defined the artist as "one urged on by instinctive needs that are too clamorous" (3I4). But it also led him to write creative literary criticism of his own, including an influential essay on "The Relation of a Poet to Daydreaming" (1908) and "The Uncanny" (I9I9), 
The use of metaphors or symbols in literature sometimes writer used the common metaphor to most speakers interpreting such associations are easy for readers of literary text, yet there are also highly personal one are used because individual's brain process perception differently and they also have different experiences. Text are always implicitly or even explicitly addressed to someone (Brooks, 1987, P. 1987).

\section{Focus of Psychoanalytic literary criticism}

The focus of Psychoanalytic literary criticism may be on one or more of the succeeding features of literary works mentioned briefly below: The "author" the theory is used to analyze the author and his/her life and his literary work as convey evidence for this analysis. This is often called "psychobiography." The "characters" the theory is used to analyze one or more of the characters. The psychological theory becomes a device that describes the characters' behavior and inspirations. The more closely the theory seems to relate to the characters the more accurate the work seems. The "audience" the theory is used to describe the appeal of the work for those who read it; the work is seen to personify common human psychological processes and motivations to which the readers react more or less unconsciously. The "text" the theory is used to examine the role of language and symbolism in the work.

The id, ego and superego which are vital parts of human psychology and originate in the conscious and unconscious part of mind and contains morals value of society as well our various desires. These desires are sometimes not accepted in society we live; they are repressed; by the time they appear in our dreams or portrayed in literary text. These dreams according to Freud are wish fulfillments that appear from different times the term "Oedipus complex" he referred to affection of boys for their mothers and want to be the replace of their fathers' desires are from childhood before age of five. Dreams are similar to literary text based on real facts as fictions need interpretations.

The psychoanalytical criticism deals with author's background and psychological studies as well portrayed by characters; the various autobiographical aspect of text may have conveyed through various methods even appeals to audience trough texts, characters, or author intentions. Holland who stated in Holland (1999) that his investigation of text related to authors have found work as manifestation of their identities, where he also observed different readers have responded differently although dynamic reading was much the same for every reader yet meaning, content and structure were all in text firm. Different readers add different interpretation to the text in poem different fantasies at moral ethic or artistic values. He claimed that the different level "exist in their different personal pattern expectation perception, fantasies, defense and transformation".

\section{Conclusion}

The human personality according to Freud is made of id, ego and superego which has made significance role in literary work and is affected through characters, reader, author and text which basses on Freud's psycho analytical criticism. The id is originated in our unconscious mind and produce the desire the anger, thirst, sexual desire and the superego is part of conscious mind as the opposite of id that give value to the moral part of the society. The two parts of personality are balanced by ego part of the personality which is aware of id as causing disorder as well the real aspect of life, thanks to the ego for not letting the clash between our morals and desire as a third party making peace between two person involved in conflict. Jung has the similar belief with Freud in many parts of personality theory yet for Freud Id is source motivation mostly related to sexual purpose but Jung believe Id can lead Individual to many ways positive and creative work.

According to Freud, the unconscious part of mind has impact in our behavior because being host for feelings of anxiety, memory, pleasure, clashes pain and etc. Yet we are not aware of them. These memories do not disappear because we repress them but these repressions affect our behaviors. We hide the feelings not necessarily mean we forget them. Jung also believe in unconscious but they think differently about nature and purpose of unconscious for Freud these memories which are placed in unconscious are mostly from the past specifically from childhood yet Jung think these memories are not only are from the past but also have future and current effects. He also thinks these memories individual's personal and also related to his/ her ancestral. What the Freud use the term "Oedipus complex" the feelings of affection of a boy to her mother which a boy is fond of her mother. These feelings happened according to Freud before the age of five and boys want to be replacing of father and similar way girls to take her mother place. The wishes repress and later appears, but we are not aware of them. "defense" is the term Freud used for these buried feelings of pleasure or anxiety yet they are appearing in our dreams. On the other hand, Jung contrary with Freud he believes there is anima which male searching his other part in the woman of his ideal and this could be in shape of mother, sister, friend etc.

According to Freud, dreams are the fulfillment of the wishes, which we have now, or we had long ago or are those wishes, we made during childhood. Freud further give examples of "Oedipus complex" a dream of the Father's death in his book The Interpretation of Dreams that the death of his father is the wish he had during the childhood to take the place of his father for the affection he had for his mother. We forgot those wishes which later fulfilled in our dreams. He also refers to the content of dreams as hidden and obvious meanings some are known for us due to their recent experience (wishes) some we don't know due to time gap between those wishes, those forgotten feelings can be associate through symbols. On the other hand, Jung believe there is archetypes shared pictures in many cultures and they are innate with individual shared with their ancestor. 
Freud refers to the "Id" as innate part of unconscious which is repressed because of "superego" our conscious awareness of the moral value of society, the "ego" which not let clash to happen at time we are going to take part in our dream life, with the help of "ego" part of our personality. There is no restriction of society in dreams "ego would help it to express feelings related to "id". In many situations, the id's desires can be fulfilled through a process of late fulfillment. The ego will ultimately let the behavior, but only in the suitable time and place. The "superego" educate our behavior as a teacher which is grow after age five and the repressed feelings could appear in our dreams in right place and time along with feelings those make our content in dreams. We act as director, actor and interpreters of our own dreams.

There is a relation of dreams and literature that's why we call it psychoanalytical criticism; these feelings of conscious and unconscious are originating in our minds. As dreams, literary work, fictions are the creations of our minds, yet centers on reality by description not completely real, similarly as text dreams also has specific reality to express and that reality can be achieved. Yet, similar to a literary work, it might need to be analyzed before that reality can be grasped. Freud claimed of individual could appreciate literary text if he/ she knows about human psychology. Psychobiography is term used for background of the author and his/ her relation to the text by which we can get great deal of information to analyze literary text. We can use Psycho analytical as device to know and describe the characters in literary work more accurately. By the help of theory, we can describe "the audience" appeal to work as common psychological motivation and inspiration to work. By the help of theory, we can analyze the role of language and symbolism used in particular text.

\section{References}

A Research Guide. (2010) Formalist Criticism retrieved from https://www.aresearchguide.com/psychoanalytic-criticism.html Adams, W. W. (200I). Making daemons of death and love: Frankenstein, existentialism, psychoanalysis. Journal of Humanistic Psychology, 4I(4), 57-89.

Adolfo \& Rossi Monti, Mario. (2010). Psychoanalysis and Art: Artistic Representations in Patients'dreams. The Psychoanalytic Quarterly, 79(3), 73I-752.

Beystehner, K. M. (1998). Psychoanalysis: Freud's revolutionary approach to human personality. Retrieved form http://www.personalityresearch.org/papers/beystehner.html

Bilcik, T. (2018,November). Freudian Slips. The Psychology Behind Slips of the Tongue, 4I65636, Retrieved 2019, April https://www.thoughtco.com/what-is-a-freudian-slip-4I65636

Bracher, Mark. Lacan, Discourse, and Social Change: A Psychoanalytic Cultural Criticism. Cornell University Press, 1993. Web. < http://joaap.org/7/leger.html>.

Bradley, Will and Charles Esche. (Ed.). Art and social change: a critical reader. London: Tate Publishing, 2007. Print.

Brooks, P. (1987). The idea of a psychoanalytic literary criticism. Critical Inquiry, I3(2), 334-348.

DAVIS, C. (n.d.) What is psychoanalytic criticism enotes Retrieved February 2019 from https://www.enotes.com/homework-help/what-psychoanalytic-criticism-discuss-some-key-373337

Encyclopædia Britannica. (2017, December) retrieved from https://www.britannica.com/science/unconscious

Encyclopædia Britannica. (2018, January) retrieved from https://www.britannica.com/science/Oedipus-complex

Freud, S. (I899). The interpretation of dreams, trans. J. Crick. Oxford University Press.(Original work published in I899.) [SL].

Freud, S. (I949). Introductory Lectures on Psycho-Analysis, trans. Joan Riviére

Freud, S., \& Strachey, J. (I9I6). The interpretation of dreams (p. 3I I526). Macmillan.

Freud, S., Jung, C. G., \& McGlashan, A. (1994). The Freud-Jung Letters: The Correspondence Between Sigmund Freud and CG Jung (Vol. I35). Princeton University Press.

Habib, M. A. R. (2008). A history of literary criticism: from Plato to the present. John Wiley \& Sons.

Holland, N. N. (I999). The story of a Psychoanalytic Critic. American Imago, 56(3), 245-259.

Hossain, M. M. (2017). Psychoanalytic Theory used in English Literature: A Descriptive Study. Global Journal of HumanSocial Science Research.

Jeneng,T.(n.d.). Psychoanalytic Criticism and Jane Eyre What Is Psychoanalytic Criticism?Retrieved from https://Www.Academia.Edu/5295078/Psychoanalytic_Criticism_And_Jane_Eyre_What_Is_Psychoanalytic_Criti cism

Jung, C. G. (19I7). On the psychology of the unconscious. Coll. wks, 7, 9-II9.

McLeod, S. A. (2017, May 05). Defense mechanisms. Retrieved from https://www.simplypsychology.org/defensemechanisms.htmPazzagli

McLeod, S. A. (2018, May 2I). Carl Jung. Retrieved from https://www.simplypsychology.org/carl-jung.html

McLeod, S. A., \& Bowlby, J. (2008). Mary Ainsworth. Retrieved https://www.simplypsychology.org/mary-ainsworth.html personalityresearch.org.(I998,August).Retrievedfromhttp://www.personalityresearch.org/papers/beystehner.html

Radowl, (2018, January). J.M. DeBord Dream Interpretation, https://dreams I23.net/anima/

Robert, M. (1968). The psychoanalytic revolution: Sigmund Freud's life and achievement. Avon. 
Rohr, Susanne and Ute Berns. "Literary and Cultural Theory." Psychoanalytic Literary Criticism. 29 November, 201 I. Web. I5 Feb, 2016. < https://www2.unihamburg.de/iaa/psycho-analysis_5.pdf>.

Shelburne, W. A. (1988). Mythos and logos in the thought of Carl Jung: The theory of the collective unconscious in scientific perspective. Suny Press.

Sollod, R. N., Monte, C. F., \& Wilson, J. P. (2008). Beneath the mask: An introduction to theories of personality. John Wiley \& Sons.

Sparknotes. (n.d.). A+ students essays retrieved from https://www.sparknotes.com/drama/oedipus/a-plus-essay/

Stangor, C., \& Walinga, J. (n.d). Introduction to Psychology-Ist Canadian Edition Introduction to Psychology-Ist Canadian Edition. Retrieved (2019,March) from https://opentextbc.ca/introductiontopsychology/chapter/2-2psychodynamic-and-behavioural-psychology/

Sugg, R. P. (Ed.). (1992). Jungian literary criticism. Northwestern University Press.

Swift, J. (1995). Psychoanalytic Criticism and Gulliver's Travels. In Gulliver's Travels (pp. 425-464). Palgrave Macmillan, New York.

Tyson, L. (20I4). P.I5 Critical theory today: A user-friendly guide. Routledge.

Wali, D. (20II) Lecture Series "Literary and Cultural Theory". Psychoanalytic Literary Criticism,II42068I Retrieved(2019,April)https://www.academia.edu/II42068I/Psychoanaytic_Literary_Criticim

\section{Copyrights}

Copyright for this article is retained by the author(s), with first publication rights granted to the journal. This is an open-access article distributed under the terms and conditions of the Creative Commons Attribution license (http://creativecommons.org/licenses/by/4.0/). 